\title{
Enhancement of Shear Strength Parameters of Clayey Soil by using Polypropylene Fiber
} Faisal Qayoom, Anuj Sachar, Manish Kaushal

\begin{abstract}
When the foundation soil is not strong enough to hold on with the loads transmitted to it .At such places the structure could be damaged, in order to eliminate this threat the soil properties such as stability, shear strength, durability etc are enhanced by mixing it with different admixtures such as lime, cement etc.At some occasions fibers (obtained from waste materials)are used to enhance the soil properties. In past a large number of studies have shown the effectiveness of such mixing materials at considerable percentages. It has been studied that the outcome of such materials when used in soil improvement techniques is handsome. In this examination the polypropylene fiber, obtained from waste materials has been used. The different percentages of fiber reinforcement are used and the corresponding changes in the shear strength parameters are examined. The effects of polypropylene fiber reinforcement on the soil samples are examined by carrying out Direct Shear Test and Unconfined Compression Test.
\end{abstract}

Keywords: Durability, Polypropylene reinforcement. Shear strength.

\section{INTRODUCTION}

Foundation plays a great role in the stability of the structure as the entire load is transmitted to the foundation. The foundation that is used to carry structural loads should be enough strong to withstand with the design loads. The soil should have adequate bearing capacity so that there is no collapse in the structure after transmission of load to it .The supporting soil must have sufficient shearing resistance so that the soil should not undergo shear failure on application of loads. Hence before the construction of any structure the properties of foundation soil are properly checked with suitable techniques. The places where the properties of soil are not suitable for the construction of structures, at such places the properties of soil are enhanced by different methods. These methods are carried out by adding different admixtures such as lime, cement, bitumen etc to the soil mass. The modern era in India began in 1960, as in India there is a shortage of petroleum products which are required in soil stabilization and its improvement, so to increase its stability and durability. As there was the shortage of the raw materials in that times the engineers started to develop new methods for the improvement in soil properties.

Revised Manuscript Received on December 30, 2019.

* Correspondence Author

Faisal Qayoom, M. Tech Scholar Department of Civil Enginering, RIMT University, Punjab, India.

Anuj Sachar, Assistant Professor, Department of Civil Engineering, RIMT University, Punjab, India.

Manish Kaushal, Assistant Professor, Department Of Civil Engineering, RIMT University. Punjab, India

(C) The Authors. Published by Blue Eyes Intelligence Engineering and Sciences Publication (BEIESP). This is an open access article under the CC BY-NC-ND license (http://creativecommons.org/licenses/by-nc-nd/4.0/)
In present era due to the increasing demand of the structures the engineers started to develop new methods, later on new research methods were developed for the soil stabilization. Here, in this examination the polypropylene fibers (obtained from waste materials) are used to enhance the engineering properties of the soil .In this investigation the shear strength parameters such as angle of internal friction and cohesion are enhanced. The enhancement of these properties in the soil has been studied at varying percentages of fiber reinforcement.

\section{Needs \&Advantages}

Soil stabilization may be defined as the procedure in which it is tainted by using appropriate technique so that we can modify its properties in order to increase its strength durability and bearing capacity. These methods can be either mechanical chemical or physical. The soil should be so stabilized so that it should posses all the engineering aspects. The main aim of the soil stabilization is to increase the stability, durability and its shear strength, the soil stabilization is also done in order to prevent the erosion and also the dust formation so as to minimize the effect of shrinkage. Soils that are having low shear strength parameters cannot withstand to the heavy loads since with the passage of time there is decrement in the shear strength parameters which may result in collapse of the entire structure. Since the soil has been properly stabilized it will be economical, cost effective, and stable and will possess a good bearing capacity. The stabilized soil will eliminate the construction of the foundations.

\section{Objectives}

The main objectives of this work are:

- The work aims at utilizing waste fiber material to enhance the shear strength parameters of soil.

- To determine the percentage of fiber by percentage of dry soil sample to be used for obtaining optimum results.

- To obtain a relationship between enhanced shear strength characteristics and percentage of fiber used in the soil sample.

\section{METHODOLOGY}

Mechanical method of Stabilization In this procedure, soils of different gradations are mixed together to obtain the desired property in the soil. This may be done at the site or at some other place from where it can be transported easily. The final mixture is then compacted by the usual methods to get the required density.

The experimental work consists of the following steps:

1. Specific gravity of soil

2. Determination of soil index properties (Atterberg Limits)

i) Liquid limit by Casagrande'sapparatus

ii) Plastic limit 
3. Particle size distribution by sievean alysis

4. Determination of the maximum dry density (MDD) and the corresponding optimum moisture content (OMC) of the soil by Proctor compaction test

5. Preparation of reinforced soil samples.

6. Determination of the shear strength by:

i) Direct shear test(DST)

ii) Unconfined compression test(UCS).

\section{Materials used}

- Soil sample

Location: Near SSM Parihaspora, Pattan Reinforcement: Polypropylene fiber Soil used is clayey soil with low plasticity. It has been collected from SSM campus Srinagar Kashmir. Polypropylene fiber used in this exploration hasenta length of $12 \mathrm{~mm}$, average diameter of $0.034 \mathrm{~mm}$ whd the sunit mass. weight of $0.91 \mathrm{gm}$ per cm cube.

\section{Specific Gravity test}

\begin{tabular}{|c|c|c|c|}
\hline sample number & $\mathbf{1}$ & $\mathbf{2}$ & $\mathbf{3}$ \\
\hline $\begin{array}{c}\text { Mass of empty } \\
\text { container }\end{array}$ & 115.83 & 117.72 & 118.35 \\
\hline $\begin{array}{c}\text { Mass of container+ } \\
\text { dried soil }\end{array}$ & 165.83 & 167.72 & 168.35 \\
\hline $\begin{array}{c}\text { Mass of container } \\
\text { dried soil + water }\end{array}$ & 396.38 & 400.02 & 401.23 \\
\hline $\begin{array}{c}\text { Mass of container+ } \\
\text { water }\end{array}$ & 365.56 & 368.52 & 370.73 \\
\hline specific gravity & 2.6 & 2.7 & 2.57 \\
\hline Avg. specific & \multicolumn{3}{|c}{} \\
\hline
\end{tabular}

\section{Liquid limit}

It may be clear as the extent of water at which the soil has capacity to get walk through with the ongoing water. At this stage the soil solids possesses very squat tangential resistance.Casagands tool is universally used as a measure to gravity

\section{Preparation of samples}

The procedure for integration of reinforcement with the soil consists of the steps as follows:- The soil elements that we are using in this investigation are compressed up to the utmost dry concentration and the proportion of water that we are using in this investigation should be the optimum water concentration. This whole process is carried out by a investigation generally known as compaction test.

The percentage of reinforcement that we use in this investigation is resoluted by the expression as below:-

$\rho \mathrm{f}=\mathrm{wf} / \mathrm{w}$

Where;

ge of reinforcement

The fraction of stabilizing material that we have been used in this examination is as $0.05 \%, 0.15 \%$ and $0.25 \%$.

\section{RESULTS AND DISCUSSIONS}

\section{Determination of Specific gravity of the soil}

Specific gravity of a substance denotes the number of times that substance is heavier than water. it as the ratio between the mass of any substance of a definite volume divided by mass of equal volume of water.

\section{Determination of index properties}

get the values of this limit.Wl is the universal sign of this state. It is the frontier which separates the plastic and liquid states.

\section{Liquid limit test result}

\begin{tabular}{|c|c|c|c|c|}
\hline Sample No. & $\mathbf{1}$ & $\mathbf{2}$ & $\mathbf{3}$ & $\mathbf{4}$ \\
\hline $\begin{array}{c}\text { Mass of empty } \\
\text { container }\end{array}$ & 14.15 & 13.61 & 14.61 & $\mathbf{3}$ \\
\hline $\begin{array}{c}\text { Mass of container }+ \\
\text { wet soil }\end{array}$ & 53.89 & 54.2 & 44.15 & 36.23 \\
\hline $\begin{array}{c}\text { Mass of container }+ \\
\text { dried soil }\end{array}$ & 41.01 & 41.72 & 27.19 & 22.46 \\
\hline Mass of solids & 26.86 & 28.11 & 11.96 & 9.42 \\
\hline Mass of pore water & 12.88 & 12.45 & 43 & 41.94 \\
\hline Water content (\%) & 47.95 & 44.39 & 27 & 32 \\
\hline Number of blows & 19 & 24 & & \\
\hline
\end{tabular}

\section{Plastic limit}

It may be clear as the percentage of water at which the soil mass starts to fissure .This limit is the intermediate limit of the plastic and partially solid condition .The limit is indicated when the soil mass initiates to get roll out on a smooth plane by forming cord like composition of radius approximately $1.5 \mathrm{~mm}$ radius. This limit is generally represented as Wp.

Now from the above results one can easily get the Plasticity index which can be determined from the following expression:-

PI = LL-PL

Where;

PI = Plasticity Index

LL = Liquid Limit

PL = Plastic Limit 
Plastic limit Test

\begin{tabular}{|c|c|c|c|}
\hline Sample No. & $\mathbf{1}$ & $\mathbf{2}$ & $\mathbf{3}$ \\
\hline Mass of empty container & 6.21 & 6.07 & 6.81 \\
\hline Mass of container+wet soil & 11.53 & 10.73 & 10.63 \\
\hline Mass of container+ dried soil & 10.61 & 9.95 & 9.97 \\
\hline Mass of solids & 4.4 & 3.88 & 3.16 \\
\hline Mass of pore water & 0.92 & 0.78 & 0.66 \\
\hline Water content (\%) & 20.9 & 20.1 & 20.88 \\
\hline Average Plastic Index & \multicolumn{3}{|c|}{20.63} \\
\hline
\end{tabular}

The above table shows the result of Plastic Limit Test ,the test was done on different soil samples and the average plastic limit was calculated and it was found to be 20.63

\section{Test on the reinforced soil sampl}

\section{Direct shear test}

The Shear test can be performed either in laboratory or in the field. This is the most commonly used test for determining the stability of the soil mass. The test is performed with different soil samples which are mostly undisturbed soil samples, disturbed samples cannot be examined by using shear test .In this test we take a soil sample and put it into the shear box ,the box consists of two halves. The sample is placed between the two halves and a confining stress is applied to the soil mass till the specimen fails at the specified strain .Now the strain produced is recorded at different intervals to determine the stress strain curve ,different specimens are tested with varying stresses so as to determine the parameters like cohesion and angle of internal friction. The confining stress is plotted on $\mathrm{x}$-axis and residual stress on $y$-axis. The intercept at $y$-axis which fits the test results is called as cohesion and the slope of that line is termed as angle of internal friction. The shear strength of the specimen is calculated by the following expression:-

$\tau=c+\sigma * \tan \varphi$

Where ;

$\tau=$ Shear strength

$\mathrm{c}=$ Cohesion

$\sigma^{*}=$ Shear stress

$\varphi=$ Angle of internal friction

Relationship between fiber reinforcement and cohesion

\begin{tabular}{|c|c|c|}
\hline S.no & $\begin{array}{c}\text { Fiber reinforcement } \\
(\%)\end{array}$ & $\begin{array}{c}\text { Cohesion (c) } \\
\mathrm{Kg} / \mathrm{cm}^{2}\end{array}$ \\
\hline 1 & $0 \%$ & 0.398 \\
\hline 2 & $0.05 \%$ & 0.501 \\
\hline 3 & $0.15 \%$ & 0.524 \\
\hline 4 & $0.25 \%$ & 0.58 \\
\hline
\end{tabular}

The above table shows the result of Direct Shear Test

- When the soil sample is not given any fiber reinforcement the value of cohesion is $0.398 \mathrm{~kg} / \mathrm{cm}^{2}$

- The value of cohesion is $0.501 \mathrm{~kg} / \mathrm{cm}^{2}$ when the soil sample is provided with a reinforcement of $0.05 \%$.

- When the soil sample is provided with $0.15 \%$ fiber reinforcement the cohesion value increases to 0.524 $\mathrm{kg} / \mathrm{cm}^{2}$.

- Similarly the value of cohesion goes on increasing with the increase in fiber content and at $0.25 \%$ the cohesion value is $0.58 \mathrm{~kg} / \mathrm{cm}^{2}$.

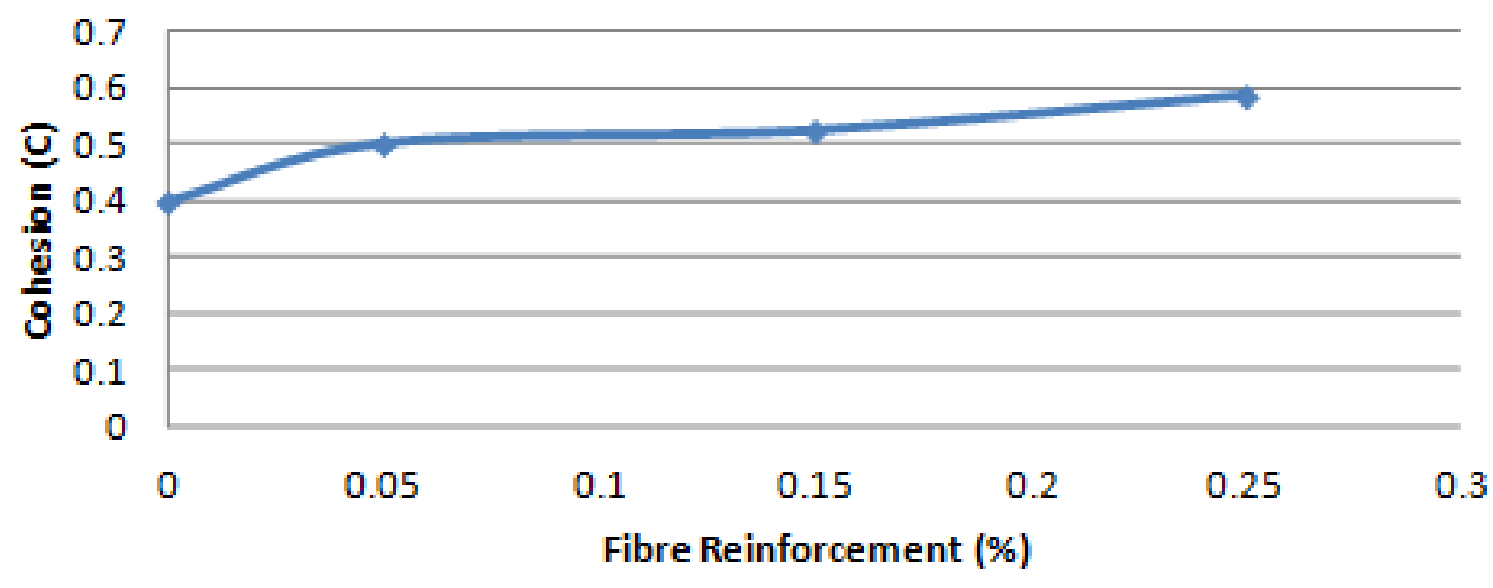


Relationship between fiber reinforcement and angle of internal friction

\begin{tabular}{|c|c|c|}
\hline S.no & $\begin{array}{c}\text { Fiber reinforcement } \\
(\%)\end{array}$ & $\begin{array}{c}\text { Angle of } \\
\text { internal } \\
\text { friction }(\Phi)\end{array}$ \\
\hline 1 & $0 \%$ & 24.41 \\
\hline 2 & $0.05 \%$ & 27.92 \\
\hline 3 & $0.15 \%$ & 30.96 \\
\hline 4 & $0.25 \%$ & 36.5 \\
\hline
\end{tabular}

The above table shows the result of Direct Shear Test .

- When the soil sample is not given any fiber reinforcement the value of Angle of internal friction is 24.41 degree.

- On providing the fiber reinforcement of $0.05 \%$ the value of Angle of internal friction is 27.92 degree.

- When the soil sample is provided with a fiber reinforcement of $0.15 \%$ the value of Angle of internal friction increases to 30.96 degree.

- Similarly the value of Angle of internal friction increases to 36.50 degree when the soil sample is provided with a fiber reinforcement of $0.25 \%$.

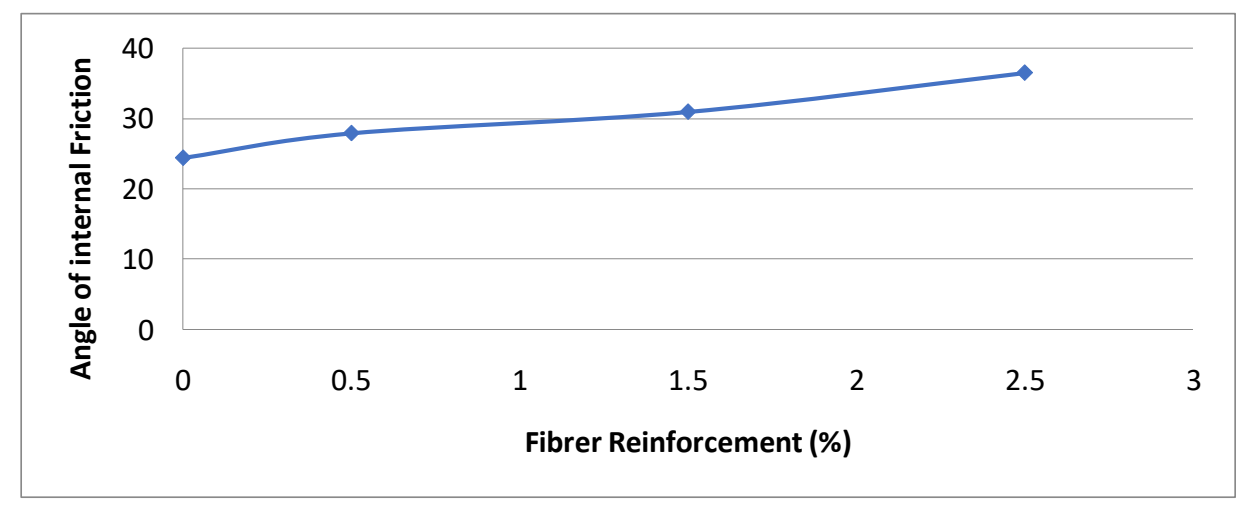

\section{Unconfined compression test}

The unconfined compression test is normally used to determine the unconfined compressive strength of the soil sample, which can be helpful in determining the shear strength of the soil sample. The apparatus consists of a cylindrical mould to which a dial gauge and a proving ring is attached. The sample is put into the cylinder and the stress is applied till the specimen fails, the deflection is measured by the proving ring attached to the test apparatus.

The unconfined compressive strength of a soil sample can be computed by the following expression:-

$\mathrm{q}_{\mathrm{u}}=\mathrm{F} / \mathrm{A}_{\mathrm{c}}$

Where; $F=$ Force applied on the sample

$\mathrm{A}_{\mathrm{c}}=$ Corrected cross sectional area.

$\mathrm{A}_{\mathrm{c}}=$ Cross sectional area $/ 1-$ strain

\begin{tabular}{|c|c|c|}
\hline S.no & Fiber reinforcement (\%) & $\begin{array}{c}\text { UCS } \\
\text { (MPa) }\end{array}$ \\
\hline 1 & $0 \%$ & 0.832 \\
\hline 2 & $0.05 \%$ & 1.13 \\
\hline 3 & $0.15 \%$ & 1.164 \\
\hline 4 & $0.25 \%$ & 1.183 \\
\hline
\end{tabular}

The above table shows the result of Unconfined Compression Test

- When the soil sample is not given any fiber reinforcement the UCS value is $0.832 \mathrm{MPa}$.

- On providing the fiber reinforcement of $0.05 \%$ the value of UCS is 1.130MPa.

- When the soil sample is provided with a reinforcement of $0.15 \%$ the value of UCS increases to $1.134 \mathrm{MPa}$.

- The value of UCS is $1.183 \mathrm{MPa}$ when the soil sample is provided with a fiber reinforcement of $0.25 \%$.

\section{Relationship between fiber reinforcement and UCS}

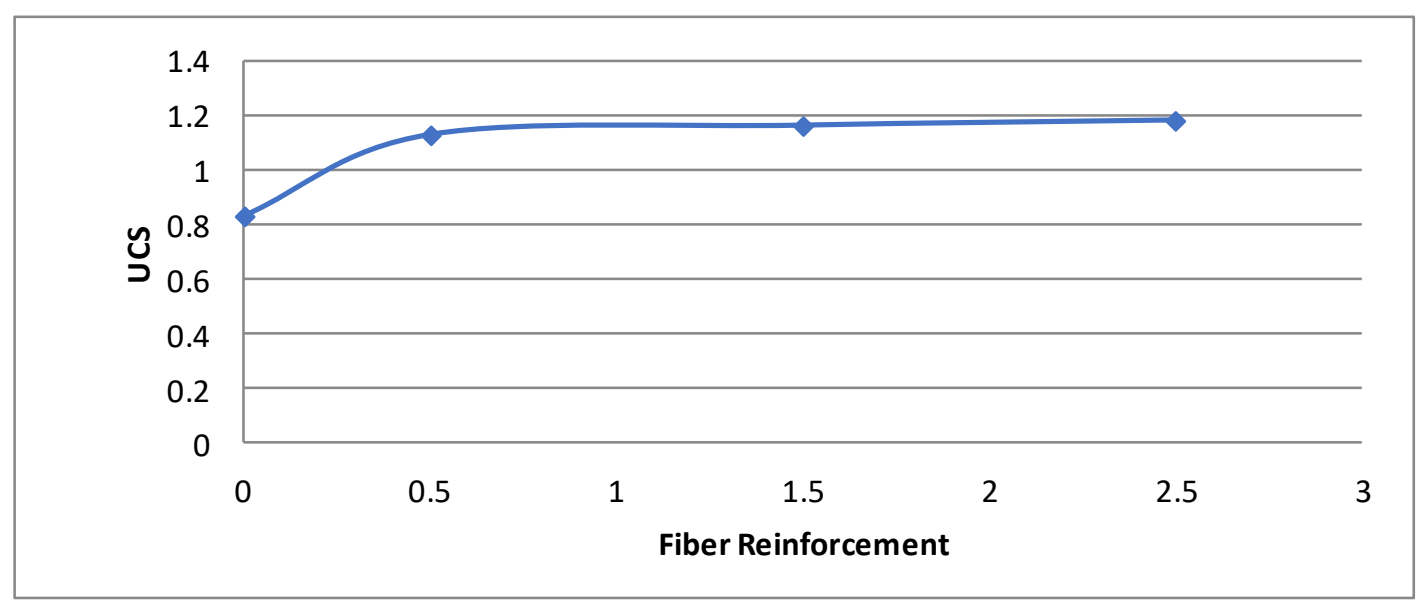




\section{CONCLUSIONS}

Based on present test study, the accompanying ends are mentioned below:

1. On conducting the shear test by using varying contents of fibers $0.10 \%, 0.20 \%$ a nd $0.30 \%$, the spreading out in the sample was found to be $25.62 \%, 4.59 \%$ and $11.83 \%$. we came to know that the expansion in the within border of $(\varphi)$ was seen as $14.37 \%, 10.89 \%$ and. $17.89 \%$.in view of the fact that the total increase in the expansion of $\mathrm{c}$ and $\varphi$ can be found to be $47.23 \%$, from $0.398 \mathrm{~kg} / \mathrm{cm} 2$ to $0.586 \mathrm{~kg} / \mathrm{cm} 2$ and $49.52 \%$, from 24.41 to 36.50 degrees individually, Therefore for stabilizing a given soil sample we have to choose a randomly distributed polypropylene.

2 . From the soil sample we concluded that the unconfined compressive strength was varying for different percentages of reinforcement .From the UCS test using $0.10 \%, 0.20 \%$ and $0.30 \%$ fiber reinforcement the unconfined compressive strength was increased upto $35.81 \%, 3.00 \%$ and $1.63 \%$ respectively from the intial value.

3 From the fiber reinforced samples we concluded that there is a net increase in the shear strength ,bearing capacity and stability in the soil mass.From the results it is clear that it is convenient to do fiber reinforcement of the soil mass in order to make it economical.

\section{REFERENCES}

2. S. A. Naeini and S. M. Sadjadi ,2008), " Effect of Waste Polymer Materials on Shear Strength of Unsaturated Clays", EJGE Journal, Vol 13, Bund k,(1-12).

3. Yetimoglu, T., Inanir, M., Inanir, O.E., 2005. A study on bearing capacity of randomly distributed fiber-reinforced sand fills overlying soft clay. Geotextiles and Geomembranes 23 (2), 174-183.

4. Chaosheng Tang, Bin Shi, Wei Gao, Fengjun Chen, Yi Cai, 2006. Strength and mechanical behavior of short polypropylene fiber reinforced and cement stabilized clayey soil. Geotextiles and Geomembranes 25 (2007) 194-202.

5. Mahmood R. Abdi, Ali Parsapajouh, and Mohammad A. Arjomand,(2008)," Effects of Random Fiber Inclusion on Consolidation, Hydraulic Conductivity, Swelling, Shrinkage Limit and Desiccation Cracking of Clays", International Journal of Civil Engineering, Vol. 6, No. 4, (284-292).

6. Consoli, N. C., Prietto, P. D. M. and Ulbrich, L. A. (1999). "The behavior of a fibre- reinforced cemented soil."' Ground Improvement, London, 3(1), 21-30. 6. IS 2720 - part (xiii) 1980-87

7. Prof. Krishna Reddy, UIC, 2008, Engineering Properties of Soils Based on Laboratory Testing

\section{AUTHORS PROFILE}

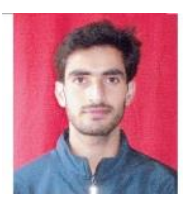

Faisal Qayoom, M. tech Scholar Department of Civil Enginering, RIMT University ,Punjab, India.

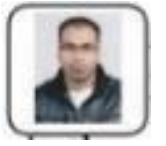

Anuj Sachar, received his B-Tech degree in civil engineering in 2008 from Punjab Technical University, Jalandhar, M-Tech from RIMT University. Presently, he is working as Assistant Professor in Author Department of Civil Engineering RIMT University, Punjab, India.

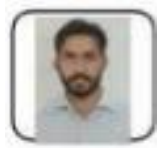

Manish Kaushal, received his b-tech degree in civil engineering in 2011 from punjab teehnical university, jalandhar, m-tech punjab from technical university, jalandhar in 2015.presently. he is working as assistant professor in department of civil engineering RIMT university. punjab, india 